\title{
Promoting effect of foliar silicon on steviol glycoside contents of Stevia rebaudiana Bertoni under salt stress
}

\author{
İlkay Yavaş (i) 1, ${ }^{*}$, Fatih Mehmet Yılmaz (iD)2, Aydın Ünay (D)3
}

\footnotetext{
${ }^{1}$ Department of Plant and Animal Production, Kocarli Vocational High School, Adnan Menderes University, Aydin, Turkey

${ }^{2}$ Department of Food Engineering, Faculty of Engineering, Adnan Menderes University, Aydın, Turkey

${ }^{3}$ Department of Field Crops, Faculty of Agriculture, Faculty of Agriculture, Adnan Menderes University, Aydin, Turkey
}

\begin{abstract}
This study investigated the effect of foliar silicon application on fresh weight and dry matter contents as well as steviol glycoside contents of stevia (Stevia rebaudiana Bertoni) grown under salt stress. In this respect, an experimental research with factorial arrangement on a Completely Randomized Design with four replications was conducted in plastic pots under greenhouse conditions. Four different salinity levels $(0,25,50$, and $75 \mathrm{mM} \mathrm{NaCl})$ were used for three weeks old seedling and two different foliar silicone concentrations (12.5 and $25 \mathrm{mM}$ ) were applied in the form of sodium silicate which was launched after 4 weeks of planting. Both $\mathrm{NaCl}$ concentrations and foliar silicone application had statistically significant effect $(p \leq 0.05)$ on fresh weight and dry matter characteristics and also on rebaudioside-A and stevioside contents of stevia leaves which were harvested before flowering period. Results showed that salt stress decreased both rebaudioside-A and stevioside contents, but foliar silicone application improve negative influences of $\mathrm{NaCl}$ treatments with even increasing the steviol glycoside contents. Rebaudioside-A content did not change, but stevioside content decreased with foliar silicone application in control conditions. However, highest rebaudioside-A and stevioside accumulation were recorded in $25 \mathrm{mM}$ foliar silicone application under $50 \mathrm{mM} \mathrm{NaCl}$ stress. In these conditions, rebaudioside-A and stevioside contents were 112 and $26 \%$ higher than control, respectively. It could be concluded that the application of silicon significantly enhanced the plants ability to withstand salt stress conditions through increased silicon content, increased steviol glycoside production. Silicon application could therefore improve crop production under salt stress.
\end{abstract}

\section{ARTICLE HISTORY}

Received: March 31, 2019

Revised: August 22, 2019

Accepted: September 24, 2019

\section{KEYWORDS}

$\mathrm{NaCl}$ stress, Rebaudioside-A, Silicon, Stevia, Stevioside

\section{INTRODUCTION}

Stevia (Stevia rebaudiana Bertoni) is a perennial medicinal plant belonging to Asteraceae family. Stevia rebaudiana contains high concentrations of steviol glycosides which give stevia a great importance, as an alternative source of table sugar [1-3]. Its leaves contain high sweetness (250-300 times greater than sucrose) due to the presence of glycosides diterpene [1,

CONTACT: İlkay YAVAŞ $₫$ iyavas@adu.edu.tr Department of Plant and Animal Production, Kocarli Vocational High School, Adnan Menderes University, Aydın, TURKEY 
4]. Despite several subunits of steviol glycosides have been identified in the literature as stevioside (SV), rebaudioside A (RbA), rebaudioside $\mathrm{B}(\mathrm{RbB})$, rebaudioside $\mathrm{D}(\mathrm{RbD})$, rebaudioside $F(R b F)$, steviolbioside $(S t b)$, rubusoside $(\mathrm{Rub})$, rebaudioside $C(\mathrm{RbC})$ and dulcoside $\mathrm{A}(\mathrm{DuA})[5,6,7]$, stevioside and rebaudioside A emerge as the most dominant steviol glycosides among others. Stevia leaves also contain considerable amounts of other components including vitamin $\mathrm{C}$, beta-carotene, niacin, magnesium, phosphorus, selenium and iron. Due to the non-caloric and sweetening properties, it is alternative to table sugar [8]. Stevia can be cultivated in semiarid climates like in Mediterranean region. Growth and yield reduction in stevia plants occur when salts accumulate in the roots due to the water stress [9]. Stevia is known to be very sensitive plant to salinity stress which affects stevia yield directly [2].

Salt stress is considered as one of the major abiotic stresses that can limit the plant growth and productivity similar to other abiotic stresses which lead to oxidative stress through the increase in reactive oxygen species $[6,10]$. Salt stress affects several important processes such as growth, protein synthesis, lipid metabolism and photosynthesis by altering the ultrastructure of the organelles, chlorophyll content and enzyme activities involved in these processes [11]. Salinity stress, which suppresses plant growth and limits crop productivity, has been continually increasing worldwide.

Silicon ( $\mathrm{Si}$ ) is accumulated by plant roots and is transported to the stems and leaves, thus exhibits mitigating effects of abiotic stresses especially salinity and drought [12]. Plants belonging to Cyperaceae and Gramineae family accumulate silicon and a better development is provided by external application [13].

Based on all the given information, the objective of this research is to evaluate the effect of $\mathrm{NaCl}$ induced salt stress (1), to investigate a possible mitigating effect of silicon under salinity conditions on the dry matter contents (2) and the percentages of stevioside and rebaudioside A of Stevia rebaudiana Bertoni.

\section{MATERIAL AND METHODS}

\subsection{Determination of fresh weights and dry matter contents}

The fresh weights of the plants were measured directly after harvesting by using sensitive balance. Dry matter contents were determined using an oven operated at $50{ }^{\circ} \mathrm{C}$ until a constant weight was obtained ( $\sim 8$ hours) [14].

\subsection{HPLC Analysis of Steviol Glycosides Extraction}

A $2 \mathrm{~g}$ dried and milled stevia leaf was weighed in a covered extraction vessel and completed up to $100 \mathrm{ml}$ with $50 \% \mathrm{EtOH}$ solution. The mixture was extracted at $55{ }^{\circ} \mathrm{C}$ within a water bath for $60 \mathrm{~min}$. After extraction, the mixtures were filtered with Whatman no:1 filter paper and supernatant was collected in falcon tubes. Finally, the supernatants were filtered through $0.45 \mu \mathrm{m}$ PVDF filter and transferred to vials before injection into HPLC.

\subsection{HPLC Analysis}

HPLC analysis was carried out using the method suggested by Jentzer et al. [15] with some modifications. Sample extracts and standards (rebaudioside A and stevioside; $10-200$ ppm) were injected into HPLC (Shimadzu Prominence LC-20A).

Column: Inertsil ODS-3 column; $250 \mathrm{~mm}$ x $4.60 \mathrm{~mm}$ x $5 \mu \mathrm{m}$ (HICHROM. UK)

Detector: UV/VIS detector (Shimadzu SPD-20A)

Wavelength: $210 \mathrm{~nm}$

Mobile phase: Acetonitrile (A) and LC-grade water with \%0.1 formic acid (B)

Column temperature and flow rate: $40{ }^{\circ} \mathrm{C}$ and $1 \mathrm{ml} / \mathrm{min} .(\% 31$ : $\mathrm{A}-\% 69$ : B; isocratic flow) 
Identification was achieved by considering the retention times of both standards and samples on the chromatogram. The amounts of steviol glycosides were then determined using the standard curves of various known concentrations of standards.

\subsection{Statistical Analysis}

All the data were statistically analysed by analysis of variance (ANOVA) using the SPSS [16]. The differences between the means were compared by least significant difference (LSD) $(p \leq 005)$.

\section{RESULTS and DISCUSSION}

This study was initially planned at the salinity doses of 25,50 and $75 \mathrm{mM}$ concentrations. However, plants with $75 \mathrm{mM}$ salinity did not grow and plants died. For this reason, $75 \mathrm{mM}$ was omitted and the results of control group $(0 \mathrm{mM}), 25 \mathrm{mM}$ and $50 \mathrm{mM}$ salinity levels were evaluated.

The main effects of salinity (A) and silicon (B) and also the interactions of $A$ and $B(A x B)$ were statistically significant $(p<0.05)$ on rebaudioside A and stevioside contents (Table 1$)$.

Table 1. ANOVA (mean squares) results of the effect of silicon under salt stress conditions on rebaudioside A and stevioside contents

\begin{tabular}{cccc}
\hline Source of Variance & df & Rebaudioside A & Stevioside \\
\hline Salt (A) & 2 & $359.78^{* *}$ & $912.06^{* *}$ \\
Error & 9 & 8.31 & 3.58 \\
Silicon (B) & 2 & $466.16^{* *}$ & $281.14^{* *}$ \\
A x B & 4 & $262.01^{* *}$ & $376.67^{* *}$ \\
Error 2 & 18 & 5.681 & 4.94 \\
General & 35 & &
\end{tabular}

**, significant at $\alpha$ levels of 0.01 .

Rebaudioside A contents were significantly affected by salt stress. Silicone application had no significant effect on rebaudioside A contents in the control pots. The effectiveness of silicone was apparent at higher salinity condition. The use of higher doses of silicon revealed higher rebaudioside A accumulation under salinity stress (Table 2). These results corroborated the Pandey and Chikara [5], who observed an increase in the rebaudioside A under higher concentration of $\mathrm{NaCl}$. Cantabella et al. [17] reported that low salt levels did not affect steviolbioside and rebaudioside A contents. Pandey and Chikara [5] demonstrated that amount of stevioside and rebaudioside A significantly increased at 50,75 and $100 \mathrm{mM} \mathrm{NaCl}$ but not at $25 \mathrm{mM} \mathrm{NaCl}$. A study carried out in Egypt showed that saline water irrigation decreased rebaudioside A contents at the second harvest [2].

Table 2. Interaction of salt stress and silicon on RebaudiosideA (g kg-1)

\begin{tabular}{lccc}
\hline & Control & Silicon $(12.5 \mathrm{mM})$ & Silicon $(25.0 \mathrm{mM})$ \\
\hline Control & $20.54 \mathrm{Aa}$ & $20.14 \mathrm{Aa}$ & $20.99 \mathrm{Ab}$ \\
Salinity $(25 \mathrm{mM})$ & $15.77 \mathrm{Bb}$ & $16.94 \mathrm{Bb}$ & $17.97 \mathrm{Bb}$ \\
Salinity $(50 \mathrm{mM})$ & $15.18 \mathrm{Cb}$ & $20.89 \mathrm{Ba}$ & $43.58 \mathrm{Aa}$ \\
\hline
\end{tabular}

LSD $0.01=3.54$

Means followed by the same lower case letters in a column and capital letters on the lines do not differ significantly by the LSD test $(p<0.05)$.

Stevioside contents decreased significantly in salinity conditions compared to control conditions but increased with silicone doses in higher salinity conditions (Table 3). Fallah et al. 
[18] found that the highest amounts of both stevioside and rebaudioside A were observed in control conditions (with $\mathrm{NaCl}$-free). In other research, it was showed that $60-90 \mathrm{mM}$ salt concentration decreased the content of stevioside and rebaudioside A [19]. On the contrary, ElHousini et al. [20] stated that the increasing salinity level in irrigation water from enhanced stevioside contents in all cutting. Besides, Shahverdi et al. [7] showed that low level of $\mathrm{NaCl}$ concentration $(30 \mathrm{mM})$ caused increasing steviol glycosides and concluded that stevia is a moderate $\mathrm{NaCl}$ tolerant plant. According to the results of other research [17], stevioside and rebaudioside A contents did not exhibit statistically significant changes in the plants treated with $2 \mathrm{~g} / \mathrm{L} \mathrm{NaCl}$, whereas $5 \mathrm{~g} / \mathrm{L} \mathrm{NaCl}$ decreased the contents of steviolbioside and rebaudioside A by $21 \%$ and $34 \%$, respectively.

Table 3. Interaction of salt stress and silicon on Stevioside (g kg-1)

\begin{tabular}{cccc}
\hline & Control & Silicon $(12.5 \mathrm{mM})$ & Silicon $(25.0 \mathrm{mM})$ \\
\hline Control & $50.91 \mathrm{Aa}$ & $41.65 \mathrm{Ca}$ & $47.03 \mathrm{Bb}$ \\
Salinity $(25 \mathrm{mM})$ & $32.92 \mathrm{Bb}$ & $31.76 \mathrm{Bb}$ & $29.83 \mathrm{Bc}$ \\
Salinity $(50 \mathrm{mM})$ & $35.90 \mathrm{Cb}$ & $39.93 \mathrm{Ba}$ & $64.21 \mathrm{Aa}$ \\
\hline LSD $_{0.01}=3.30$ & & &
\end{tabular}

Means followed by the same lower case letters in a column and capital letters on the lines do not differ significantly by the LSD test $(p<0.05)$.

The main effects of salinity (A) and silicon (B) and also the interactions of A and B (AxB) were statistically significant (Table 4).

Table 4. Analysis of variance (mean squares) of the effects of silicon under salt stress conditions on fresh weight and dry weight

\begin{tabular}{cccc}
\hline Source of Variance & df & Fresh weight & Dry weight \\
\hline Salt (A) & 2 & $208.92^{* *}$ & $2.23 * *$ \\
Error & 6 & 1.09 & 0.013 \\
Silicon (B) & 2 & $90.41^{* *}$ & $1.15 * *$ \\
A x B & 4 & $18.68^{* *}$ & $1.29 * *$ \\
Error 2 & 12 & 1.091 & 0.018 \\
General & 26 & & \\
\hline
\end{tabular}

**, significant at $\alpha$ levels of 0.01 .

High doses of salinity caused a significant reduction in fresh weights in plants. The highest values were obtained with $12.5 \mathrm{mM}$ silicone application in high salinity conditions. The lowest value was observed at highest salinity application with silicone free treatment (Table 5). These results are consistent with Shahverdi et al. [7] stating that $\mathrm{NaCl}$ stress caused reduction fresh and dry weights of leaf. Noori Akandi et al. [21] reported that fresh weight of leaf and dry weight of root decreased linearly when $\mathrm{NaCl}$ concentration increased in the growing media. According to Pandey and Chikara [5], $\mathrm{NaCl}$ application significantly decreased fresh weight of leaf at $100 \mathrm{mM}$ concentration. Reis et al. [9] reported that increasing concentration of $\mathrm{NaCl}$ declined total fresh weight of leaf.

They concluded that only one harvest of stevia plant is possible even if the irrigation is well applied at high salinity. However, twice harvesting would be possible in low salinity conditions because of the lower salinity accumulation in soil compared to high salinity treatment. 
Table 5. Interaction of salt stress and silicon on fresh weight $(\mathrm{g})$

\begin{tabular}{lccc}
\hline & Control & Silicon $(12.5 \mathrm{mM})$ & Silicon $(25.0 \mathrm{mM})$ \\
\hline Control & $25.87 \mathrm{Bb}$ & $29.62 \mathrm{Ab}$ & $28.05 \mathrm{Ab}$ \\
Salinity $(25 \mathrm{mM})$ & $29.70 \mathrm{Ca}$ & $34.91 \mathrm{Aa}$ & $31.12 \mathrm{Ba}$ \\
Salinity $(50 \mathrm{mM})$ & $15.83 \mathrm{Bc}$ & $26.02 \mathrm{Ac}$ & $25.10 \mathrm{Ac}$ \\
\hline
\end{tabular}

LSD $0.05=1.86$

Means followed by the same lower case letters in a column and capital letters on the lines do not differ significantly by the LSD test $(p<0.05)$.

The high level of salinity caused significant decreases in dry matter contents of the plants. The highest dry matter contents were observed in $12.5 \mathrm{mM}$ silicone inclusion under $25 \mathrm{mM}$ salinity conditions. The lowest value was obtained from high salinity conditions without silicone (Table 6). Salt stress has been reported to decrease fresh and dry weight of Cape gooseberry plants. The use of silicon $\left(1.0 \mathrm{~g} \mathrm{~L}^{-1}\right)$ has alleviated the influence of salinity $(0.5 \%$ $\mathrm{NaCl}$ ) on chlorophyll, carotenoids, stomatal density and leaf blade thickness. When salt stress was about $1.0 \%$, silicon was not effective [10]. Similarly Zeng et al. [19] reported that stevia plants treated with 90 and $120 \mathrm{mM} \mathrm{NaCl}$ showed significantly lower leaf fresh/dry weight and shoot dry weight than control conditions. The total dry weight decreased by $40 \%$ at $120 \mathrm{mM}$ $\mathrm{NaCl}$ treatment. Pandey and Chikara [5] stated that Stevia Rebaudiana responds least resistant to increasing salinity conditions but also reported the optimum $\mathrm{NaCl}$ concentrations as 50 and $75 \mathrm{mM}$ for healthy plant growths.

Table 6. Interaction of salt stress and silicon on dry weight (g)

\begin{tabular}{cccc}
\hline & Control & Silicon $(12.5 \mathrm{mM})$ & Silicon $(25.0 \mathrm{mM})$ \\
\hline Control & $4.90 \mathrm{Aa}$ & $5.08 \mathrm{Ac}$ & $4.93 \mathrm{Aa}$ \\
Salinity $(25 \mathrm{mM})$ & $5.11 \mathrm{Ba}$ & $6.06 \mathrm{Aa}$ & $5.07 \mathrm{Ba}$ \\
Salinity $(50 \mathrm{mM})$ & $3.55 \mathrm{Cb}$ & $5.45 \mathrm{Ab}$ & $4.26 \mathrm{Bb}$ \\
\hline LSD 0.05=0.240 & \\
\hline
\end{tabular}

\section{CONCLUSION}

The use of silicone adapted the negative effects of salinity stress applied to stevia and also increased stevioside and rebaudioside A contents significantly. Generally, the prominent conditions for the fresh weight and dry matter contents were 12.5 and $25 \mathrm{mM}$, silicone and $\mathrm{NaCl}$ concentrations, respectively. On the other hand, the lowest values were observed under $25.0 \mathrm{mM}$ salinity concentration without silicon application. The results of this research showed that $25.0 \mathrm{mM}$ silicon treatment had the desired influence on mitigation of the negative influences of $50 \mathrm{mM}$ salinity on stevia. The use of exogenous silicon could be an alternative to ameliorate the generated stress. Therefore, the increase of salt tolerance was incorporated with the Steviol glycoside that allowed stevia plants to cope better with salt stress. Finally, it is suggested that salt-affected soils with high doses of silicon are more suitable for growth of stevia plant with higher stevioside and rebaudioside A contents.

\section{ORCID}

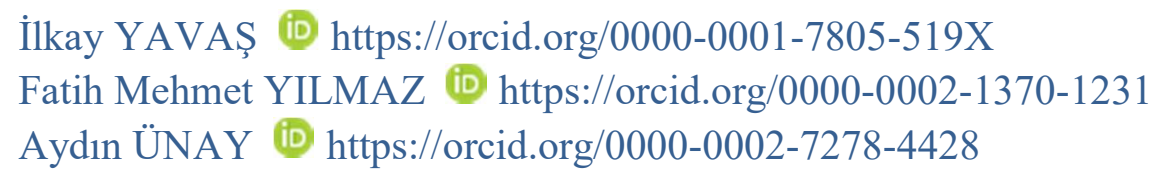




\section{REFERENCES}

[1]. Zaman, M.M., Chowdhury, M.A.H., Chowdhury, T. 2015. Growth parameters and leaf biomass yield of stevia (Stevia rebaudiana Bertoni) as influenced by different soil types of Bangladesh. Journal of the Bangladesh Agricultural University, 13 (1), 31-37.

[2]. Ahmed, S.A., Ibrahim, A.K., Gouda, M.S., Mohamed, W.W., Khattab, S. (2016). Diatomite alleviates the adverse effects of salinity stress on growth and yield of Stevia rebaudiana. International Journal of Advanced Biotechnology and Research, 7 (1), 10-21.

[3]. Benhmimou, A., Ibriz, M., Al Faïz, C., Douaik, A., Khiraoui, A., Amchra, F.Z., Lage, M. (2017). Productivity of new sweet plant in Morocco (Stevia rebaudiana Bertoni) under water stress. Journal of Medicinal Plants Studies, 5(5), 126-131.

[4]. Hamad, A.M. (2015). Productivity of Stevia Rebaudiana Bertoni Plant and its Affective by Salinity, Nitrogen and Potassium Fertilization. J. Plant Production, Mansoura Univ., 6 (9), $1543-1552$.

[5]. Pandey, M., Chikara, S.K. 2015. Effect of salinity and drought stress on growth parameters, glycoside content and expression level of vital genes in the steviol glycosides biosynthesis pathway of Stevia rebaudiana (Bertoni). Int. J. Genet., 7 (1), 153-160.

[6]. Helmy, B.F., Abdelsalam, N.R., Ghonema, M.A., Khalid, A.E. 2016. Morphologgical Changes and Antioxidant Activity of Stevia rebaudiana under Salt Stress. Alexandria Science Exchange Journal, 37 (2), 326-336.

[7]. Shahverdi, M.A., Omidi, H., Tabatabaei, S.J. (2017). Stevia (Stevia rebaudiana Bertoni) responses to $\mathrm{NaCl}$ stress: Growth, photosynthetic pigments, diterpene glycosides and ion content in root and shoot. Journal of the Saudi Society of Agricultural Sciences, 18 (4), 355-360. Doi.org/10.1016/j.jssas.2017.12.001

[8]. Rachmawati, D., Sudjino, Asiyah, I.J. 2017. Response and Stevioside Levels of Stevia (Stevia rebaudiana Bertoni) Grown At Different Light Intensity and Water Availability. Pak. J. Bot., 49(5), 1689-1695.

[9]. Reis, M., Coelho, L., Santos, G., Kienle, U., Beltrão, J. (2015). Yield response of stevia (Stevia rebaudiana Bertoni) to the salinity of irrigation water. Agri Water Manag., 152, 217-221.

[10]. Rezende, R.A.L.S., Rodrigues, F.A., Soares, J.D.R., de Oliveira Silveira, H.R., Pasqual, M., de Maria Gomes Dias, G. (2018). Salt stress and exogenous silicon influence physiological and anatomical features of in vitro-grown cape gooseberry. Ciência Rural., 48 (1), 1-9.

[11]. Abbaspour, H., Afshari, H., Abdel-Wahhab, A. (2012). Influence of salt stress on growth, pigments, soluble sugars and ion accumulation in three pistachio cultivars. J. Med. Plants Res., 6 (12), 2468-2473.

[12]. Ziv, M. (2010). Silicon effects on growth acclimatization and stress tolerance of bioreactor cultured Ornithogalum dubium plants. Acta Hortic., 865, 29-35.

[13]. Kumar Tripathi, D., Pratap Singh, V., Ahmad, P., Kumar Chauhan, D., Mohan Prasad, S. (2016). Silicon in Plants. Advances and Future Prospects. 1st Edition. CRC Press. 392 pages

[14]. Abdulameer, D.A., Osman, M.B., Sulaiman, Z., Yusop, M.R., Abdullah, S., Azizi, P., Muttaleb, Q.A. (2018). Assessment of Stevia rebaudiana Bertoni Genotypes via Morpho Agronomic Traits under Two Light Conditions. American Journal of Plant Sciences, 9 (7), 1403-1413.

[15]. Jentzer, J.B., Alignan, M., Vaca-Garcia, C., Rigal, L., Vilarem, G. (2015). Response surface methodology to optimise Accelerated Solvent Extraction of steviol glycosides from Stevia rebaudiana Bertoni leaves. Food chemistry, 166, 561-567.

[16]. SPSS Inc. (1999). SPSS for Windows: Base 10.0 Applications Guide. Chicago, Illinois 
[17]. Cantabella, D., Piqueras, A., Acosta-Motos, J.R., Bernal-Vicente, A., Hernandez, J.A., 210 Díaz-Vivancos, P. (2017). Salt tolerance mechanisms induced in Stevia rebaudiana Bertoni: Effects on mineral nutrition, antioxidative metabolism and steviol glycoside content. Plant Physiology and Biochemistry, 115, 484-496.

[18]. Fallah, F., Nokhasi, F., Ghaheri, M., Kahrizi, D., Beheshti Ale, A.A., Ghorbani, T., Kazemi, E., Ansarypour, Z. (2017). Effect of salinity on gene expression, morphological and biochemical characteristics of Stevia rebaudiana Bertoni under in vitro conditions. Cell Mol Biol (Noisy-le-grand). 63(7), 102-106. doi: 10.14715/cmb/2017.63.7.17

[19]. Zeng, J., Chen, A., Li, D., Yi, B., Wu, W. 2013. Effects of salt stress on the growth, physiological responses, and glycoside contents of Stevia rebaudiana Bertoni. J. Agric. Food Chem., 61, 5720-5726.

[20]. El-Housini, E., Ahmed, M.A., Hassanein, M.S., Tawfik, M.M. (2014). Effect of Salicylic Acid (SA) on Growth and Quality of Stevia (Stevia rebaudiana Bert.) Under Salt Stress. American-Eurasian J. Agric. \& Environ. Sci., 14 (4), 275-281.

[21]. Noori Akandi, Z., Pirdashti, H., Yaghoubian, Y., Ghasemi Omran, V. (2017). Quantifying the response of growth and physiological parameters of stevia (Stevia rebaudiana Bertoni) medicinal plant to salinity stress under controlled conditions. J. Sci. \& Technol. Greenhouse Culture, 8(1), 10-19. 